\title{
Increasing air pollution and its impact on human health
}

\author{
Tauseef Ahmad*i
}

Department of Epidemiology and Health Statistics, School of Public Health, Southeast University, Nanjing (210009), China

\section{Correspondence}

Tauseef Ahmad, Department of Epidemiology and Health Statistics, School of Public Health, Southeast University, Nanjing (210009), China

Email: Tauseef.ahmad@hu.edu.pk

History

- Received: 04 June 2019

- Accepted: 07 June 2019

- Published: 09 June 2019

DOI :

https://doi.org/10.15419/ajhs.v5i1.453

\section{Check for updates}

\section{Copyright}

(C) Biomedpress. This is an openaccess article distributed under the terms of the Creative Commons Attribution 4.0 International license.

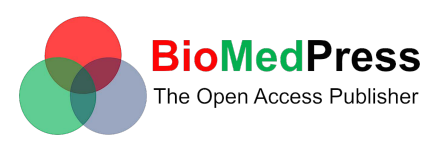

\section{DEAR EDITOR-IN-CHIEF,}

In 2019, World Health Organization (WHO) considered air pollution as the greatest risk to human health. Since, the beginning of $20^{\text {th }}$ century, urbanization has increased greatly and its role in economic sector and social development is very clear but as a consequence altering our planet in ways that pose current threats to environmental and human health. Every day, out of ten nine people breath polluted air. Every year, an estimated 7 million people prematurely died from stroke and cancer, heart and lung diseases ${ }^{1}$. In 2015, 4.2 million deaths were attributed to ambient air pollution (Particulate Matter $\mathrm{PM}_{2-5}$ ) and 103.1 million disability-adjusted life-years. In addition, exposure to ozone caused an approximately 254000 deaths. Over the past 25 years, deaths attributed to PM2-5 has increased significantly with an alarming rate. In 1990, an estimated 3.5 million deaths were reported where in 2015 the total number of deaths reached to 4.2 million $^{2}$. In 2016, from indoor air pollution (household exposure to smoke from dirty cookstoves and fuels) an estimated 3.8 million deaths were reported $^{1}$. Majority of the deaths were reported from low and middle-income countries. In these countries, the air pollution is attributed to high volume of industry emissions, power generation, fuels for transportation, and human activities like cooking and heating used coal, wood, straw and dung produce high level of indoor smoke. The polluted air consists tiny and microscopic pollutant can penetrate through circulatory and respiratory system.

Globally, air pollution has been significantly associated with various health problems like lung and heart diseases, heart attacks, stroke (ischaemic stroke and haemorrhagic stroke), lung cancer, chronic obstructive pulmonary disease (COPD), and premature mor- tality $^{2-4}$. In recent years, due to massive industrialization an increased has been seen in air pollution resulted significant adverse effect on all kind of life includes plant, animal and aquatic life, human and environmental health. Of global greenhouse gas emissions, transportation is responsible for $(23 \%)$. Since, 2000 , transportation emissions has significantly reduced in Europe but still need to go a long way ${ }^{5}$. There is an urgent need of new policies and management to reinforce and emphasis on control use of coal, vehicle and industrial emissions standard, fuel consumption limits, energy saving policies, environmental protection laws, massive tree plantation and other associated factors with air pollution should be considered on priority basis to control the burden of disease in near future.

\section{CONFLICT OF INTEREST}

None

\section{REFERENCES}

1. World Health Organization. Air Pollution. Available from: https://www.who.int/airpollution/en/. (Accessed: May 2019).

2. Cohen AJ, Brauer M, Burnett R, Anderson HR, Frostad J, Estep K. Estimates and 25-year trends of the global burden of disease attributable to ambient air pollution: an analysis of data from the Global Burden of Diseases Study 2015. Lancet. 2017;389(10082):1907-18. 28408086. Available from: 10.1016/ S0140-6736(17)30505-6.

3. Shah AS, Langrish JP, Nair H, McAllister DA, Hunter AL, Donaldson K. Global association of air pollution and heart failure: a systematic review and meta-analysis. Lancet. 2013;382(9897):1039-48. 23849322. Available from: 10.1016/ S0140-6736(13)60898-3.

4. Shah AS, Lee KK, McAllister DA, Hunter A, Nair H, Whiteley W. Short term exposure to air pollution and stroke: systematic review and meta-analysis. BMJ. 2015;350:h1295. 25810496. Available from: 10.1136/bmj.h1295.

5. undefined OECD/ITF. Reducing transport greenhouse gas emissions: trends \&amp; data 2010. Germany: OECD/ ITF; 2010.
Cite this article : Ahmad T. Increasing air pollution and its impact on human health. Asian J. Health SCi.; 5(1):9. 